\title{
Implantação de software BIM em curso de arquitetura
}

\author{
BIM application in course of architecture
}

\author{
> Álvaro José Paiva de Almeida \\ PUC Minas Brasil \\ alvaropaiva@pucminas.br
}

\begin{abstract}
This paper presents partial results from a process of a BIM application in the third period of the Architecture course of PUC Minas from August 2011. The study refers to a learning experience. It is, methodologically, an experimental research. The software learning process happens parallel to the design process. The students have to design a little house, with help of all disciplines of the period. The great advantage of BIM in the design process is that obtaining the details, cuts, plants, etc. occurs from detailed digital model of the building.
\end{abstract}

Keywords: BIM - Building Information Modeling; Desenho Digital; Desenho Arquitetônico; Projeto integrado; Metodologia de Projeto.

\section{Introdução}

O trabalho apresenta resultados parciais de um processo de implantação do BIM - Building Information Modelling no curso de graduação de arquitetura da PUC Minas - Pontifícia Universidade Católica de Minas Gerais, em Belo Horizonte, Brasil. O estudo se refere a uma experiência didática; metodologicamente, trata-se de uma pesquisa experimental.

A partir do $2^{\circ}$ semestre de 2011, no $3^{\circ}$ Período foi implantado o BIM e neste período desenvolve-se um trabalho integrado pelas disciplinas de Trabalho Integrado III, Representação III, Modelos Digitais III, Projeto III e História de um de um projeto de uma casa mínima com até $45 \mathrm{~m}^{2}$.

Dentre as limitaçóes verificadas na implantação constatou-se que o período de um semestre é insuficiente para o desenvolvimento dos projetos complementares: hidráulica, elétrica e estrutura; entretanto foi possível desenvolver o projeto de arquitetura, com a modelagem tridimensional e na obtenção dos detalhes, plantas, cortes, etc. juntamente com a estrutura, movimentação de terra e fundaçáo. Foi possível, também, explorar as ferramentas de renderização e animação tridimensional, assim como, da simulação do estudo solar.

Os professores têm verificado um real ganho no processo de ensino aprendizagem com a utilização do BIM, além do emprego de outros métodos de representação, como croquis, detalhes manuais e modelos físicos nas etapas de criação e desenvolvimento. Os alunos não têm se furtado em enfrentar o desafio de projetar uma arquitetura, levando em conta todos os condicionantes sociais, topográficos, técnicos, climáticos, e outros.

\section{Metodologia e processo de trabalho}

Desde a implantação do BIM no curso de arquitetura, cerca de 360 alunos já passaram pelo processo. A metodologia de escolha do software REVIT, para desenvolvimento do trabalho na PUC Minas se deu a partir de análises comparativas entre os mais utilizados. Observou-se qual melhor programa adaptaria ao trabalho integrado de projeto elaborado no $3^{\circ}$ período, bem como, à sequência de estudos de softwares gráficos utilizados no curso desde o $1^{\circ}$ período. O REVIT, por exemplo, dentre os softwares analisados, era o que melhor representava a superfície topográfica (aspecto importante no trabalho, sobretudo, pelo fato do curso estar localizado em regiáo de topografia acidentada e este ser um aspecto abordado no trabalho).

$\mathrm{O}$ processo de aprendizado do software não se dá dentro de um método propedêutico, mas sim, paralelo ao processo de projeto que é realizado de forma integrada entre as disciplinas do período. Ou seja, os alunos aprendem a projetar e desenhar concomitantemente. Dessa forma, os alunos ficam mais atentos no momento de aprendizagem das questóes técnicas, gráficas, já que percebem as demandas das mesmas e suas deficiências no projeto que vêm desenvolvendo.

\section{0 curso de arquitetura da PUC Minas}

O Curso de Arquitetura e Urbanismo da PUC Minas tem duração de 10 semestres e carga horária de 4290 horas, são oferecidas 60 vagas por semestre para o turno da tarde e 40 no noturno. A matrícula é feita por disciplina e estruturado em dois ciclos - o Básico e o Profissionalizante, de acordo com as indicaçóes das Diretrizes 
Curriculares Nacionais do Curso de Graduaçâo em Arquitetura e Urbanismo (Resolução n. 6 / 2006 da Câmara de Educação Superior do Conselho Nacional de Educação) e finalizado pelo Trabalho de Curso, denominado Trabalho Final de Graduaçáo - TFG (Projeto pedagógico, 2008).

O Ciclo Básico tem como ênfase o desenvolvimento de projetos interdisciplinares, enquanto no Ciclo Profissionalizante, náo existe uma sequência pré-determinada, ou seja, não há pré-requisito entre as disciplinas do ciclo.

O Ciclo Básico, que compreende os $1^{\circ}, 2^{\circ}$ e $3^{\circ}$ períodos, tem como metas principais: receber o aluno e fazer o reconhecimento deste; adaptar os procedimentos didático-pedagógicos as suas características; trabalhar a sensibilização dos alunos para os problemas fundamentais da arquitetura e do urbanismo; desenvolver a capacidade operacional em representação gráfica do espaço, assim como a leitura e a expressão oral e escrita. As disciplinas de cada período deste ciclo desenvolvem um trabalho integrado, segundo um grande tema por período: no $1^{\circ}$ período - a cidade, $2^{\circ}$ período - arquitetura e no $3^{\circ}$ período - o corpo. Além das metas descritas anteriormente, o ciclo objetiva dar condiçóes ao aluno de ingressar no Ciclo Profissionalizante.

\section{0 trabalho integrado do $\exists^{\circ}$ periodo}

O trabalho desenvolvido pelo conjunto das disciplinas é o projeto de uma casa mínima com até $45 \mathrm{~m}^{2}$. A proposta de elaborar um projeto de arquitetura em dimensóes menores é para possibilitar investigar a arquitetura em sua plenitude, um estudo em que " $a$ concepção da forma adotada como seminal é a de uma forma entendida como estrutura essencial e interna, como construção do espaço e da matéria. Dentro desta concepção, forma e conteúdo tendem a coincidir. O termo estrutura seria a ponte que interligaria os diversos significados da forma" (Montaner, 2002).

$\mathrm{Na}$ organização do período, cada disciplina tem um papel a cumprir isoladamente, o momento de convergência se dá, semanalmente, na disciplina de Trabalho Integrado III. Os três professores: de Representação III, Modelos Digitais III e Projeto III lecionam juntos na disciplina Trabalho Integrado na forma de um grande ateliê. Discutem-se os diversos aspectos comuns na condução do projeto e os conteúdos que serão ministrados nas demais disciplinas, bem como a realizaçáo das bancas de avaliação. Além da disciplina de Trabalho Integrado como ponto de convergência das demais, há uma articulação bem definida nos planos de ensino e em um calendário do semestre comum, com a marcaçâo das datas das bancas, visita ao terreno e exposição ao final do semestre. Após o término das aulas, os professores passam por um período de duas semanas de avaliaçáo dos resultados obtidos e do processo de ensino-aprendizagem

O Trabalho Integrado deve se pautar na linguagem corporal e suas práticas de representaçóes estéticas (já que o tema norteador do $3^{\circ}$ Período é o corpo). O corpo como suporte das linguagens visuais contemporâneas interpretadas a partir do ponto de vista espacial e das novas mídias. A partir dessa investigação baseada no desenvolvimento de modelos tridimensionais, obtém-se detalhes, plantas, cortes, e os alunos desenvolvem, também, croquis de con- cepção e detalhes. O projeto é apresentado, inicialmente, para uma banca formada com o corpo de professores do período em meados do semestre sendo discutido, analisado e apresentadas sugestóes, se necessário. Ao final do semestre, o projeto (após revisóes apontadas pela banca) é apresentado para a comunidade acadêmica, por meio de um vídeo, na exposição de trabalhos acadêmicos, em que são expostos os trabalhos de todos os períodos.

\section{A disciplina de Modelos Digitais III}

Inicialmente, o objetivo da disciplina Modelos Digitais III era trabalhar métodos de representação gráfica e animação avançadas; porém, ao longo do tempo se percebeu que o foco da representação gráfica da arquitetura estava mudando e não era mais importante apenas fazer uma perspectiva renderizada ou uma animação tridimensional, o foco agora é a simulação. Os modelos digitais de arquitetura devem ser úteis para permitir a simulação de várias questôes como: a insolação, a estrutura, conforto ambiental, acústica, etc. A arquitetura vem se tornando cada vez mais complexa, as exigências em infraestrutura, equipamentos, componentes, legislaçóes, tomam cada vez mais tempo durante o processo de projeto, assim, a representaçáo em si, não ocupa a centralidade no processo como há 30 anos atrás. Os arquitetos precisam cada vez mais de tempo para dedicar à simulaçáo, ter um controle maior dos resultados do projeto após execução e existem vários softwares desenvolvidos para arquitetura para elaborar estas simulaçóes como o Robot Structural Analysis Professional e o Ecotec Analysis da Autodesk. No desenvolvimento do Projeto da Arena das Dunas situado na cidade de Nata-RN no Brasil, fez-se um modelo tridimensional no Revit e, posteriormente, a simulação do conforto ambiental com o Ecotec (http:// www.autodesk.com.br). Neste aspecto, os softwares para arquitetura caminham na trilha aberta pelos softwares de desenho mecânico, mas, com relativo atraso, pois os softwares como o CATIA ou Solidworks permitem modelar as peças tridimensionalmente, obter vistas e seçóes diretamente do modelo e a simulação de rigidez, resistência, quantidade de material para fundir as peças. Há bastante tempo, os modelos digitais na indústria mecânica são a base da fabricação e do processo de construção e estấo no lugar de desenhos convencionais, e na arquitetura observa-se tal fenômeno. Mesmo o processo CADCAM, que na indústria mecânica, automobilística e aeronáutica é mais evidente, e está sendo experimentado na arquitetura em componentes e no processo de construçáo. Como exemplo, podese citar o processo de construção do auditório para conferencias do DG Bank, em Berlim, Alemanha que foi concebido na forma de uma cabeça de cavalo, modelado no CATIA pelo arquiteto Frank Gehry e seus componentes foram fabricados no processo CADCAM, tal qual uma fuselagem de aviāo (LINDSEY, 2001).

O pouco tempo disponível para discussão e elaboração dos projetos na concepção formal de uma residência, mesmo que em pequenas dimensóes (considerando todos os aspectos, como: a estrutura, vedação, cobertura, mobiliário até a movimentação de terra, etc. bem como a representação gráfica dentro das normas da ABNT deste projeto) necessitaria de um software que viabilizasse tal proposta. Segundo Szalapj, a tecnologia segue uma demanda do projeto, mais que o projeto se ajustar à nova tecnologia. " $A$ novidade da atual tecnologia é a capacidade do computador de nos ajudar 
com nossos esboços e ideias, para desenvolver os temas, para facilitar os desenhos para produção, racionalizar os controles ambientais e para acelerar o processo de construção. Ela não usurpa o ato da criação: não é o deus ex machina do teatro que é a arquitetura" (SZALAPAJ, 2005).

\section{Desenvolvimento do trabalho}

O projeto é desenvolvido em um terreno existente. Atualmente, a área de estudo está localizada no bairro Dom Cabral, situado na cidade de Belo Horizonte e o trabalho inicia-se pela visita ao terreno, orientada por todos os professores e os alunos observam os condicionantes físico/espaciais, bem como os condicionantes socioeconômicos do bairro onde o lote se insere.

$\mathrm{Na}$ disciplina de Projeto III, os alunos desenvolvem "pesquisa sobre os modos de habitar, com ênfase em casas-minimas ou compactas que iluminem a reflexão sobre a relação entre corpo e espaço; as dimensóes quantitativas e qualitativas do espaço arquitetônico em diferentes contextos sócio-culturais; a inter-relação entre sistema construtivo, forma e linguagem arquitetônica e análise do lugar em que se localiza o lote onde deverá ser implantada uma casa minima, para um potencial habitante verossimil, plausivel, definido a partir da observação crítica das práticas sociais, dos usos e apropriaçóes do espaço urbano pelos usuários em questão" (Plano de Ensino de Projeto III, 2014).

Paralelamente ao desenvolvimento do projeto, na disciplina de Modelos Digitais III se introduz o estudo de modelagem tridimensional digital no Revit, e logo na primeira unidade se modela uma arquitetura por completo, obtendo a partir do modelo digital as plantas, cortes, fachadas e tabelas. A arquitetura é modelada desde a fundação à cobertura, estrutura de telhado e movimentação de terra - superfície topográfica, platôs, taludes, arrimos e rampas.

$\mathrm{Na}$ disciplina de Representação III são desenvolvidos croquis de plantas, cortes, bem como, a elaboração de desenhos à mão livre de detalhes arquitetônicos e o estudo de representação de coberturas e estruturas de telhados.

A grande vantagem do BIM no processo de projeto no $3^{\circ}$ período é a obtençáo dos detalhes, cortes, plantas, que são realizadas a partir do modelo digital da construção. Para que estes detalhes gráficos sejam gerados com bastante precisão e de acordo com as normas técnicas, os modelos devem ser bem elaborados com muitas informaçôes, assim, todas as questôes devidas à construção passaram a ser mais evidentes dentro das discussôes em sala de aula.

O processo vem sendo acompanhado de análises qualitativas dos resultados por meio de discussóes e entrevistas com os professores do período e dos períodos seguintes, também são realizadas entrevistas com alunos egressos do $3^{\circ}$ Período afim de verificar, segundo a opiniáo destes, os resultados do processo de aprendizagem e se continuam utilizando o BIM no Ciclo Profissionalizante. O Revit é eficiente, sobretudo na fase de desenvolvimento; porém, o software ainda não corresponde muito bem na fase inicial de criação, e nesta etapa, os croquis manuais ainda são um importante meio de projeto.

\section{Resultados}

Os professores têm verificado um real ganho no processo de aprendizagem com a utilizaçáo do Revit e do emprego de outros métodos de representação, como croquis, detalhes manuais e modelos físicos nas etapas de criação e desenvolvimento.

Em pesquisa realizada em 2014, com os alunos do Ciclo Profissionalizante do $4^{\circ}$ ao $9^{\circ}$ período, em que a escolha do software para desenvolvimento dos projetos fica a critério do próprio aluno, observou-se que a escolha BIM (Revit) foi de $25 \%$ dos alunos ao contrário da pesquisa anterior, em 2011, em que era nula (foram mencionados outros softwares como: AutoCAD, Sketch up, Lumion, TQS, Rhino, Grasshopper, Big Data, Archcad, Ftool e Vector Works).

\section{Discussão}

O processo de ensino do projeto se dá concomitante à aprendizagem do desenho; assim, muitas vezes, o aluno se vê no desafio de projetar uma forma que ainda náo sabe representa-la graficamente e com isso, passa a ter uma atitude mais autônoma e demanda, nas disciplinas de desenho, tópicos necessários ao aprofundamento do seu próprio projeto. Desta forma, verifica-se um estudante mais interessado e atuante em sala de aula, simultaneamente, utiliza plenamente as ferramentas do BIM impulsiona compreender o funcionamento interno do mesmo e incentiva o usuário a lidar com códigos paramétricos. Por exemplo, o domínio da ferramenta de modelagem de uma escada exige conhecer e entender as normas municipais e, até, a fórmula devido a Blondell (cujo escopo compóe um dos parâmetros da ferramenta de execuçáo de escadas no REVIT).

Outro aspecto importante, é que, está sedimentando o caminho para a elaboração de simulaçôes de conforto ambiental e estrutura com outros softwares, como o Ecotect e o Robot ambos da Autodesk. Tais análises poderão ser realizadas em uma etapa mais à frente no Curso de Arquitetura, no Ciclo Profissionalizante.

No filme Sketches of Frank Gehry, o arquiteto comenta que não gostava do desenho arquitetônico para pensar a arquitetura, porque o desenho chamava mais atençáo para si do que para a arquitetura, por isso preferia a maquete física. No BIM, tal qual o entendimento de Gehry, a ênfase está na modelagem do protótipo da arquitetura, ou seja, a sua representação arquitetônica (plantas, cortes e fachadas) é consequência. Esta característica do BIM é extremamente útil em um processo de ensino e aprendizagem de projeto de arquitetura, sobretudo, para um aluno em início de curso que ainda não tem maturidade sobre o tema e o raciocínio espacial desenvolvidos.

\section{Bibliografia}

AutoDesk. http://www.autodesk.com.br).

Eastman, Chuck. (2011). BIM Handbook. A guide to building information modeling for owners, managers, designers, engineers and contractors. New Jersey, publicação John Wiley \& sons.

Kolarevic, Branko. (2003). Architecture in the digital age: design and manufacturing. Spon press, New York, USA.

Lima, Claudia Campos. (2012). Revit Architecture 2012. Editora Erika, São Paulo.

Lindsey, Bruce. (2001). Digital Gehry. Material Resistance. Digital Construction. Birkhauser, Boston, UK.

Ministério Da Educação. Conselho Nacional De Educação. Câmara De Educação Superior. (2006, Resolução nº6). Diretrizes 
Curriculares Nacionais do Curso de Graduação em Arquitetura e Urbanismo.

Montaner, Josep Maria. (2002). As formas do século XX. Barcelona: Gustavo Gili.

Monteiro, Igor Mendes. (2012). O uso dos sistemas BIM em projeto de arquitetura: Diversificação de soluçôes versus padronização. Dissertação de Mestrado. Universidade de Brasília, Brasília.

Picon, Antoine. (2010). Digital Culture in Architecture. An introduction for the design professions. Birkhauser, Berlin.
Pontifícia Universidade Católica De Minas Gerais. (2008, p. 56). Projeto Pedagógico do Curso de Arquitetura da PUCMINAS, 2008. Belo Horizonte.

Pontifícia Universidade Católica De Minas Gerais. (2014). Plano de Ensino de Modelos Digitais III, 2012. Belo Horizonte.

Sketches of Frank Gehry.(2005). Direção: Sydney Pollack. Produção: Sydney Pollack. Nova York, SONY Pictures, (86 min).

Szalapaj, Peter. (2005). Contemporary Architecture and design process. Elsevier, Oxford, UK. 